\title{
My New School: transition to high school for children with special educational needs in England - findings and ideas for practice
}

\section{Helena Bunn,}

Email Helena.bunn@norfolk.gov.uk

\section{Lauren Boesley,}

AQ1

While transition from primary to secondary school is an exhaustively researched area, there is limited research into how the ideas and insights of children, particularly those with Special Educational Needs (SEN), could inform or guide successful school transition planning. The current article presents the final stage of an action research project in which a transition intervention was designed by students in collaboration with their schools and educational psychology services. The intervention, 'My New School', was initially piloted in an inner-city primary school in England (see Bunn, Davis and Speed 2017) and since has developed into a working tool for several other schools. Children's views, alongside those of school staff, were used to inform the final design of 'My New School' intervention. The article explores findings from analysing the participating children and school staff, alongside relevant literature, and final discussions and implications for practice conclude.

Keywords

transition

special educational needs

coproduction

educational psychology

pupils

\section{Introduction and background}


Transition within pupils' education is a well research phenomenon, with a significant focus on the move from primary to secondary school. Such transition embodies a number of changes across academic, social and structural levels, alongside emotional and social adjustment following physical relocation (Tobbell, 2014; Waters, Lester \& Cross, 2014); it brings changes in school size, class structure, academic expectations and student autonomy, as well as in student diversity and peer and staff relationships, as students move from the top of one to the bottom of another complex social hierarchy (Anderson, Jacobs, Schramm \& Splittgerber, 2000; Hebron, 2017).

Transition is recognised as a process involving anxiety and concern for much of the student population (Galton, Gray \& Ruddock, 1999; Galton et al., 2003; Tobell, 2003; West et al., 2010; Zeedyk et al., 2003). Successful transition, while difficult to define, can be measured across different dimensions, including: academic performance and engagement; behaviour in the classroom; and social relationships with peers (Anderson et al., 2000); improved confidence and self-esteem; eased parental concern; increasing interest in school and school work; steady adjustment to new routines and school organisation; and curriculum continuity (Evangelou et al., 2008).

Research on the impact of transition on education outcomes has consistently identified 'dips' in attainment during periods of transition, both within the UK and internationally (Bellmore, 2011; Galton et al., 1999, 2003; McGee, Ward, Gibson \& Harlow, 2003; Stoll et al., 2003). Reports commissioned by the UK Department for Education and Employment found that almost half of students in English and Science (49\% across both subjects) and a third of students in Mathematics (33\%) made no progress in the year following their move from primary to secondary school (Galton et al., 1999, 2003).

Supporting students in transition is important for those with special educational needs (SEN), who find transition particularly challenging (Anderson et al., 2000; Galton et al., 1999; Hodson, Baddeley, Laycock \& Williams, 2005; Lovey, 2002; West et al., 2010; Zeedyk et al., 2003; Rice et al., 2013). Within the UK, children and young people with SEN represent $14.4 \%$ of the student population (DfE, 2017) and enabling these children to meet their full potential is framed by statutory policy and legislation (Children and Families Act, 2014; DfE \& DoH, 2015). Whilst students with SEN have reported similar concerns to the wider population 
of children (Maras \& Aveling, 2006), lower levels of social support, lower academic self-esteem and higher peer victimisation or bullying than typically developing peers have also been identified (Foely, Foley \& Curtin, 2016; Hughes et al., 2013; Topping, 2011). Moreover, the social, emotional or academic needs of students with SEN can be amplified through the transition process (Hebron, 2017; Topping, 2011; West et al., 2010) and their anxieties can persist longer into secondary, than those of other pupils (Hughes et al., 2013; Zeedyk et al., 2003). Unresolved, the long-term impact of social and emotional difficulties can continue, often more severely into adulthood (Jones, 2013; West et al., 2010; Waters et al, 2012).

To date, there is limited information into how children's ideas and insights, particularly those with SEN, could inform or guide successful transition planning. Bunn, Davis and Speed (2017) aimed to address this gap by using insights of pupils with SEN to develop a transition intervention (My New School). The programme was initially piloted and has developed into a working tool for several other schools.

\section{Study aim and method}

The current study aimed to improve what was My New School pilot intervention, by using the opinions of Special Educational Needs Coordinators (SENCOs) who implemented the intervention, as well as the views and experiences of some of the pupils with SEN who took part in the programme. Three SENCOs who had implemented My New School intervention in their primary school and a focus group of six pupils who had participated in these interventions were directly involved in the study. Additionally, secondary information consisting in brief evaluations of 15 (year 6) students who completed My New School were also considered. Results were analysed using inductive thematic analysis (Braun \& Clark, 2006).

British Psychological Society's (2014) and local authority's ethical guidelines were adhered to when selecting the participants, gathering and analysing the data. Data was analysed by two researchers using inductive thematic analysis (Braun \& Clarke, 2006) and accounts provided in the findings sections used S-1 to S-3 for SENCO related information and C-1 to $\mathrm{C} 6$ for child related information.

\section{Findings}


Analysis of the data available yielded three themes relating to the effective implementation of My New School (Figure 1): (1) The lead up to transition: planning and preparation; (2) The intervention experience: session delivery; and (3) The transition story: starting high school.

Fig. 1

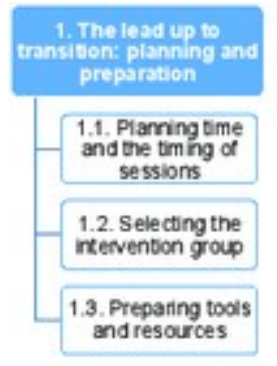

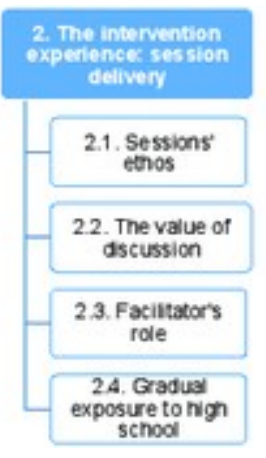

SENCO and student experiences of the My New School transition intervention: Themes and subthemes

\section{The lead-up to transition: planning and preparation}

Within the first theme, three important subthemes emerged (Figure 2), described briefly below.

Fig. 2

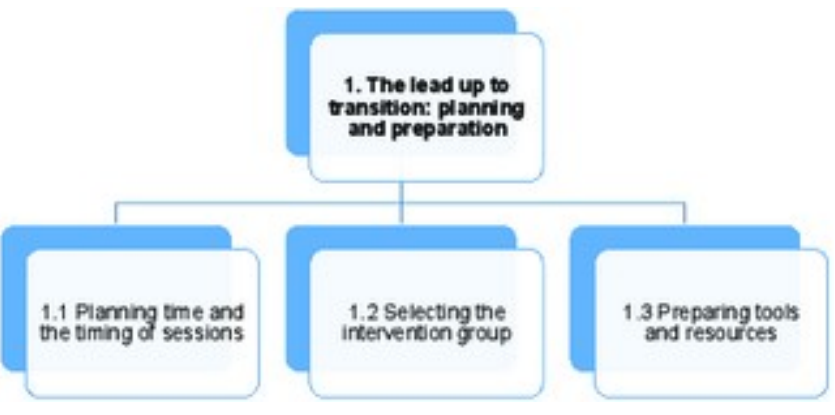

Subthemes related to lead up to transition: planning and preparation

Planning time and the timing of sessions was a challenging, but essential, part of the process. Participants suggested that sessions should be timetabled after Year 6 exams but emphasised that preparation should begin early and spread over the year. Although the number of sessions varied between schools, flexibility was central: "the first year we did six sessions, last year we did four ... six was nice and comfortable but maybe somewhere in the middle" (S-2). 
Selecting the intervention group was another interesting finding. Although the intervention focused on students with SEN, participants thought group selection should be based on individual need and not a SEN label: "not just choosing children because they had SEN" (S-3). Whilst identifying appropriate students was important, group dynamics was also found relevant: "I think it's about selecting a group that will work well together (...) and understanding the intervention may not be suitable for every child" (S-1).

Preparing tools and resources was another factor considered to be important; using technology to find information about high school was found relevant: "using the iPads, using things from the websites was really useful" (S-2), although physical resources may also provide alternative means for research: "maybe collecting a bit more stuff in advance, like the high school prospectuses (...) in case the technology isn't working" (S-1).

\section{The intervention experience: session delivery}

This theme yielded four subthemes (Figure 3).

Fig. 3

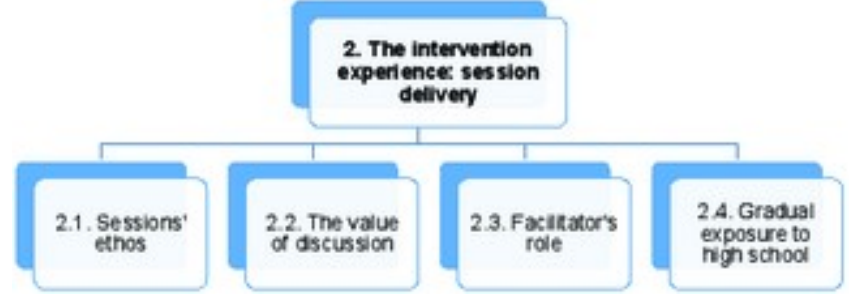

Subthemes related to the intervention experience: session delivery

Sessions adopting a flexible, child-centred approach, was important in successful interventions. For SENCOs, it was essential that My New School booklet guided session delivery and prompted discussion yet maintaining adaptability: "follow the very general structure but they might want to tweak or add something that's very specific to them or the school" (S-1). Additionally, the students found that the sessions fostered a sense of excitement: "I don't know about you guys but it got me quite excited to go up to high school" (C-1) and made them better prepared for transition: "you were fully able to calm down and when it got closer you'd be able to just relax and feel more confident going into high school" (C-5). 
Intervention - Interestingly, the intervention was not about completing $M y$ New School booklet, but about facilitating discussion: "it was the conversations around what was in the book that was useful, rather than finding out the actual information" (S-3); "it was also nice to, when we did drawing and things it would be drawing, but it would also be chatting at the same time" (C-1); "you should never introduce a rule of silence" (C-2). Discussion enabled students to share their feelings and lessen anxiety, provide clarity and demystify high school: "they always come up with myths and legends" (S-1).

Facilitator's role was another important component of the intervention: "it (...) helped children really develop and support their confidence" (S-3); particularly for encouraging meaningful discussion. The facilitator was not about directing information or answers, but to support students with problem-solving strategies: "we talked about how would they tell somebody if they needed some help ... it was more the positives and how you are going to solve that" (S-2).

Gradual exposure to high school was especially important for students, as some felt overwhelmed by the larger open days: "I didn't actually feel that confident on induction week ... you start to get to know the school but you still think or you still feel a bit closed in" (C-3); "it would have also helped to go back on a different day or a different session - come back here and walk around the entire school to where you could have food and where the toilets are" (C-2). As well as visits to high school, inviting key secondary staff and students to primary school could support the transition: "the SENCO is going to come here and do meetings with parents and children as well. We're trying each year to tweak it a little bit so it's better" (S-1); "we should go and tell them it's OK" (C-4).

\section{The transition story: starting high school}

Within this last theme, four important subthemes emerged (Figure 4).

Fig. 4

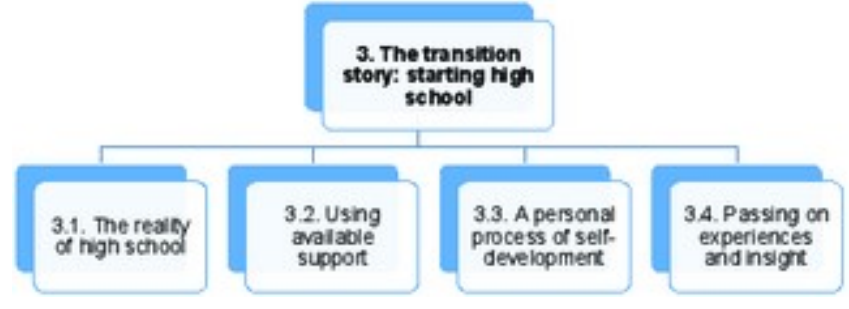

Subthemes related to the transition story: starting high school 
Within the reality of high school, students identified several experiences that were difficult to prepare for, despite the intervention. This included a greater workload, particularly homework: "at first you get loads of homework" (C-3); "there's on average about five bits of homework a week" (C-2). This could be a challenging adjustment from primary school and some felt more preparation within primary school could support this change: "I think we should slowly get - not get more and more, but get more used to having homework before high school" (C-4).

Additionally, the impact of increased school size, with large student numbers could amplify feelings of anxiety or helplessness: 'there's big groups of people and there's you on your own and you just feel really vulnerable' (C-3). Despite site visits or open days, students found orientating high school challenging and getting lost was common: 'I was afraid to walk around the school because I didn't know my way, I didn't know where to go' (C-4). This experience could increase feelings of vulnerability: 'you're just lost and you feel smaller than you already are' (C-5).

Challenges associated with transitioning into the bottom of the school hierarchy were also difficult to prepare for: "the older kids think they are better than you" (C-4), with experiences that varied in significance: "people think it's funny to take the mick" (C-5), "when I first got here, loads of times, you ask someone who's older than you where to go and they take you to the wrong place" $(\mathrm{C}-1)$; “(...) and getting shoved down the stairs" (C-6). Experiences could be mentally and physically unsettling: "you're the shortest and you're the smallest and you're the easiest to push around and you get shoved up on the walls" (C-1). Students found these situations an unavoidable part high school: "you need to be prepared to be teased ... it's just something you have to deal with" (C-2).

Using available support systems is seen to mitigate challenges associated with high school: "somethings do make it easier to come up, if you have a really good friendship group or, I've got a sister in Sixth Form and she's been here for ages" (C-1). For socio-emotional concerns, students identified strategies for accessing support: "the pastoral manager will never say no when something is wrong with you, they'll always acknowledge that you feel hurt by a comment that someone's said" (C-2); and demonstrated knowledge of outside agencies for more serious events: "sometimes you get referred to actual proper sessions outside of school, 
and the evenings and you can talk about some things that are bothering you" (C-1).

While using available support could alleviate some transition challenges, students wanted the capability to face difficulties independently: "you need to build up confidence to make sure you know what you're actually doing" (C-3), becoming involved in a personal process of self-development. This process takes time: "you first feel shy and then, as you slowly and slowly progress, you start to break out of your shell a little bit and see what it's all about really" (C-4); "half of you wants to say, "let's go to a classroom and ask a teacher where I need to be", and the other half of you is saying, "you don't need to do that, you need to be more responsible, you can find it yourself"” (C-3).

Last but importantly, students felt it was difficult to understand the reality of high school without going through it: "I feel like you're never actually going to know what the school's like unless you go here" (C-1). They reflected that passing on experience and insight by enabling Year 7 students to share their experiences with Year 6 students could help prepare others for the move, but not make them panic: "I think the thing is to not scare the younger ones, because things do happen, I think it's good to acknowledge that, but also, it's very rare" (C-2). Facing challenges was key for developing confidence, resiliency and independence: "no matter how confident you feel, you still sometimes feel - not unsafe - but you still feel vulnerable" (C-4).

\section{Discussion}

Data analysis highlighted several focal points for the effective implementation of My New School. Three key themes (the lead-up to transition - planning and preparation; the intervention experience - session delivery; and the transition story - starting high school) were highly suggestive that the intervention should not be treated as a time limited experience, but more as a longer process starting in year 6 and finishing in year 7 . The three themes are discussed below in the light of the literature already available, alongside implications for practitioners.

\section{The lead-up to transition: planning and preparation}

SENCOs' reflections related to allowing time to prepare and introduce students to transition support Jindal-Snape and Foggie's (2008) report that many parents and professionals thought students could benefit from earlier preparation. Indeed, students' level of preparedness has been identified as 
an integral factor for facilitating successful transitions; in a conceptual framework for understanding and improving school transition, Anderson et al. (2000) explored transition success or failure alongside factors of preparedness and support. The less prepared a student was for transition, the more support was required to facilitate the process. Both preparedness and support relate to academic, emotional or social outcomes highlighting the need for comprehensive and carefully planned efforts. Cauley and Jovanovich (2010) identified five factors for developing an effective transition programme including: continuous planning and communication among a diverse planning team; incorporation of social and academic concerns into programmes; utilisation of a range of activities; continuity of support from primary to secondary; and particular support given to more vulnerable students. Following this system can support the effectiveness of My New School.

Selecting the intervention group is another crucial factor, with views that intervention groups should be selected based on need rather than SEN label and include those with high anxiety or low confidence. West et al. (2010) also argued that students' personal characteristics were central to their transition experience. Within their study, students with lower self-esteem and academic ability experienced poorer school transitions that impacted future attainment and depression levels by age 15. Irrespective of SEN label, this included students who were anxious, felt less prepared for secondary or had experienced victimisation. On predicting successful and difficult transitions, Rice, Frederickson and McManus (2015) argued that no single group was more vulnerable to poorer transition. Rather, a range of risk and protective factors were associated with outcomes, including gender, socio-economic status, learning motivation, parental concerns and levels of psychological wellbeing.

Selecting a group that worked well together could also impact intervention outcomes. Reflecting on Tuckman's model of group development (1965), new groups go through stages that enable them to grow, face challenges, find solutions and meet goals. Understanding these stages can help teams become effective more quickly. Tuckman's model has framed further investigation into complex group dynamics and remains an accessible starting point for understanding group function and effectiveness (Rickards \& Moger, 2000; Whetten \& Cameron, 2007). The intervention's emphasis on group discussion, combined with time limited nature of the process, means that prior knowledge of student dynamics may expedite the group 
development process. This may be achieved through collaboration with staff, and indeed, with students themselves.

\section{The intervention experience: session delivery}

My New School aimed to provide students with opportunities to explore and discuss feelings and strategies around transition, within a flexible, child-centred ethos of session delivery. Fundamentally, listening to children and young people is supported by policy, including the United Nations Convention on the Rights of the Child (1989), the Children and Families Act (2014) and the Department for Education's Special Educational Needs and Disabilities (SEND) Code of Practice (2015). Within transition, students' views have been identified as a valuable resource to inform and contribute to improvements; research, however, has repeatedly identified a mismatch between adult and pupil perceptions on transition challenges (Galton \& Morrison, 2000). School staff concerns have focussed on learning or attainment outcomes while students have expressed greater concern around social-emotional factors (Ashton, 2008). As a result, school strategies for managing transition that focus on organisational or administrative processes may satisfy school objectives, but may not acknowledge or meet student's needs (Topping, 2011). To manage transition, personal and social concerns must be understood, addressed and incorporated into processes (Jindal-Snape \& Foggie, 2008), moving focus away from academic attainment and towards fostering a sense of security (Scanlon et al., 2015). Within the current study, the impact of a flexible, child-centred ethos resulted in student reports of increased confidence and optimism about high school.

Additionally, discussions, enabling students to share their anxieties and problem-solve solutions collectively, were seen to have a significant impact on easing students' concerns and improving confidence. To understand the impact of collaborative discussion within My New School, principles behind cooperative learning and Social Interdependence Theory can be explored and applied (Johnson \& Johnson, 1989, 2005). Cooperative learning occurs where students work together to collectively complete tasks with mutual benefit; supporting and encouraging one another, taking responsibility for their own and others' learning, and using group social skills to meet aims (Johnson \& Johnson, 1989, 1999). This approach can positively impact academic, social and emotional outcomes, including reduced bullying or victimization and higher engagement or attainment (Johnson \& Johnson, 2002b; Van Ryzin \& Roseth, 2018). Social Interdependence theory posits that creating a positive context of 
social interdependence is crucial for enabling cooperative learning (Johnson \& Johnson, 2005). The use of the discussion described by participants within My New School are consistent with a cooperative learning approach, in which students work collaboratively to find strategies for managing transition. In this sense, competition is removed as students promote each other's success - giving and receiving help, information and feedback (Johnson \& Johnson, 2002a). Additionally, self-organised learning can be used to explore the value of discussion (Dolan et al., 2013; Harri-Augstein \& Thomas, 1991; Mitra and Dangwal, 2010; Mitra, 2012; Thomas \& Harri-Augstein, 1985). Self-organised learning enables students to use conversation, collaboration and thinking tools to problem-solve and construct personal meaning from learning (Lee Looi Chng \& Coombs, 2004), encouraging students to work together using the internet to answer a series of questions. The facilitator has minimal input, taking on a mediator role to encourage feedback or refection during discussion (Mitra, 2012). Self-organised learning promotes learning through conversation at two levels: through internal reflection within the individual, and through external discussion with others (Thomas \& Harri-Augstein, 1985). While individuals develop these skills, the facilitator must create an open, flexible and non-judgmental environment that enables the construction and reconstruction of personal meaning through conversation (Lee Looi Chng \& Coombs, 2004). Similarly, My New School aims to empower students to take responsibility for their development by identifying their needs and strategies, evaluating outcomes and reflecting on the process. This learnercentred approach, in which students are responsible for their behaviour and learning, can promote self-directed, independent and lifelong learning and problem-solving skills.

The facilitator was also found crucial for enabling meaningful discussion in My New School. Facilitating cooperative learning involves constructing a learning environment where students can facilitate each other's development (Ballantine \& Larres, 2007). Within My New School, the facilitator takes on a mediating role over directive teaching, encouraging learning and development through peer interaction. This approach represents a shift from traditional pedagogy that has historically emphasised a teacher-student dyadic over co-learning between peers (Johnson \& Johnson, 2008; Jolliffe, 2007). A mediation approach reflects what Blatchford, Kutnick, Baines and Galton (2003) describe as social pedagogy. Framed by social constructionist underpinnings of Piaget (1959) and Vygotsky (1978), social pedagogy explores how peer relations and group interactions impact learning and development, with improvements 
reported in academic progress, pupil interaction and high-level discussion (Baines, Blatchford \& Chowne, 2007; Baines, Rubie-Davies \& Blatchford, 2009). Blatchford et al. (2003) outline four key dimensions where the facilitator can apply strategies for maintaining a social pedagogy: (1) the classroom context: preparing the classroom and the groups; (2) interactions between children: preparing and developing pupil skills; (3) the teacher's role: preparing adults for working with groups; and (4) tasks: preparing the lessons and group work activities. Within these dimensions, the facilitator is instrumental in strategically organising groups and tasks and mediating interactions to enable positive outcomes. Although social pedagogy was developed within a classroom context, the underlying principles can arguably apply to interventions like My New School where an emphasis on group work and peer-peer learning is integral.

Last, gradual exposure to high school was seen to alleviate transition anxiety and improve confidence in My New School. This process included familiarisation with physical or logistical aspects of high school, as well as social relationships between staff and peers. Evangelou et al. (2008) endorsed gradual transition exposure, arguing that visits to and from schools were simple, practical strategies for supporting students. Within their study, students who felt supported in settling in through visits, tours and taster-days were more likely to report a successful transition. Integrating social support strategies have also improved adjustment, including mentors for new students and starting Year $7 \mathrm{~s}$ before older groups (Coffey, 2013; Evangelou et al., 2008). The gradual exposure to school represents a practical element of the intervention that can be explored through behavioural principles underpinning systematic desensitization (Wolpe, 1958). Traditionally used to overcome fears or phobias, individuals incrementally challenge fears, build confidence and develop skills to overcome anxiety. Traditionally, systematic desensitization has three stages: creating an anxiety hierarchy, learning relaxation skills, and pairing relaxation with stressful situations. The gradual exposure to high school can be likened to this hierarchical process. Students begin by thinking and talking about high school transition and as sessions progress, exposure and contact with schools increase as students' research, plan routes, meet key staff, and visit new environments. Reflecting on systematic desensitization, the incorporation of relaxation skills or meditation into My New School could be explored. The benefits of these practices include improved stress management, self-awareness and emotional coping (Wisner, 2014), lower anxiety and higher resilience (Wendt et al., 2015). While setting and delivery of techniques can impact 
their effect (Waters, Barsky, Ridd \& Allen, 2015), relaxation skills may provide students with additional, practical methods for easing transition anxiety.

\section{The transition story: starting high school}

When reflecting on the reality of high school, participating students described challenges that complemented existing literature: increased workload or homework (Rice et al., 2010; Zeedyk et al., 2003); the impact of increased school size such as getting lost and crowds (Ashton, 2008; Galton \& Morrison, 2000); and difficulty transitioning to the bottom of the school hierarchy (Hebron, 2017; Zeedyk et al., 2003). Transition is a challenging process, representing interruptions across academic, social and structural levels (Anderson et al., 2000; Tobbell, 2003; Waters et al., 2014). Increased anxiety, reduced attainment and social difficulties are common across the student population (Galton \& Morrison, 2000; Hebron, 2017; Neal et al., 2016), with greater detrimental impact reported for students with SEN (Bloyce \& Frederickson, 2012; Maras \& Aveling, 2006; Scanlon et al., 2015). Consistent with research (Ashton, 2008; Rice et al., 2011; Scanlon et al., 2015), learning issues were rarely raised by participating students, suggesting that academic concerns may be less important than socio-emotional factors, regardless of SEN. Consistent with previous literature (Graham \& Hill, 2003; Lucey \& Reay, 2010; Measor \& Woods, 1984; Zeedyk et al., 2003), transition anxiety was often coupled with a sense of excited anticipation, with students expressing optimism around their growing confidence and independence. Lucey and Reay (2000) argued that research tends to focus on the negative function of anxiety associated with transition, but it is equally important to recognise the positive, developmental function of this process. Lucey and Reay $(2000 ; 2010)$ suggest that transition challenges, and the associated anxiety, were central to developing coping strategies, gaining autonomy and independence, and constructing a strong sense of self (Lucey \& Reay, 2000).

Participating students identified support that alleviated challenges, yet aspired the confidence to face challenges independently. Students' personal process of self-development described the process of becoming independent and autonomous, an expression of agency known as selfdetermination - an individual's ability to define and achieve their goals (Hui \& Tsang, 2012). Self-determination theory (Deci \& Ryan, 1985) posits that constructive psychological development can occur when an individuals' three fundamental needs of autonomy, competence and 
relatedness are met (Deci \& Ryan, 2000; Ryan \& Deci, 2000). Within education, students experience autonomy when they can explore, take initiative and problem-solve independently; feel competence when faced with challenges and receive feedback; and experience relatedness when they feel listened to and included (Hoffman \& Field, 1995). Meeting these needs can enable students to be intrinsically motivated to engage in their learning environment, supporting academic engagement and learning outcomes (Niemiec \& Ryan, 2009). Within a SEN context, Wehmeyer's (1999) functional model of self-determination suggested that students can become causal agents over their lives when they are enabled to demonstrate behavioural autonomy, self-regulated behaviour, selfrealisation and psychological empowerment. Field \& Hoffman (2002) suggest that schools should support this process by creating an environment that is implicit and explicit in skills, knowledge and attitudes for developing self-determination.

Finally, this study suggests that passing on students' experiences and insight could support transition by informing others about the realities of high schools. This process may help support Year 6 students and also forms part of the wider transition story for Year 7 students. Reissner (2004) suggested that sharing each other's "stories" can enable individuals to learn from and adapt to changing roles and relationships (nb: here "story" is defined as a personal account of an experience within a setting, as per Reissner, 2008b). This complex process often involves multiple stories being carried out simultaneously which form part of a longer, ongoing story (Reissner, 2008a). Within the context of the current study, transition represents part of a student's wider story, and individual experiences or challenges within this process all contribute to the student's self-development. This act of passing on experiences and insight reflects a coaching approach, where Year 7 students, in effect, become mentors for other students. Reissner (2008a) suggested that sharing narratives can help those in a coaching role make sense of their story and create an effective interaction with those they are sharing with. By sharing experiences, students can communicate knowledge and learning that can enable both themselves and others to make sense, understand and prepare for change (Reissner, 2008a).

\section{Conclusions and implications for practice}

This study reinforced what some could argue are well established views and overly searched approaches in educational psychology. This may well be true and the authors do not claim to have revolutionised the area of 
school transition. This said, the whole process was a positive, enhancing, experience for all those participating in this study and the action research process emphasised significant insights from students and school practitioners, who so neatly match contemporary literature and ethos.

Because of the participants' powerful messages, the authors believe that the practical implications of this study are slow and long-lasting in the geographical area in which it has been undertaken. It started as a pilot, captured the interest of some other schools and currently there are discussions about promoting My New School as a county wide intervention. There are also plans about publishing the intervention with its accompanying facilitator's manual for wider use.

For the interest of knowledge and practice, three main implications of this study were considered important by the authors:

- Those willing to use My New School transition intervention should allocate sufficient time for it and should avoid treating it as a time limited intervention including only the steps within the booklet, but approach it as an active process, with due attention for preparation, the process of the actual intervention, and meaningful links with the high school. Because of this the authors considered it essential to provide a facilitator's manual to accompany the booklet.

- Features of the facilitator were found to be essential in the success of the sessions. This means that, if My New School is to be run by school, within school, choosing a mindful, child focused facilitator is very important in the success of the intervention. The facilitator's skills will dictate, to some extent, the selection of the student group.

- Last but very importantly, those wishing to have successful outcomes should not ignore the significant resource of the children identify it, value it and grow it! The study also identified the importance of narratives in coaching peers; it is hence important to tap on such resource and use students as peer mentors to provide greater insight for those going through school transition.

\section{References}

Anderson, L., Jacobs, J., Schramm, S. and Splittgerber, F. (2000) School transitions: beginning of the end or a new beginning? International Journal of Educational Research, 33, 325-339. 
Ashton, R. (2008) Improving the transfer to secondary school: how every child's voice can matter. Support for Learning, 23, 4, 176-182.

Baines, E., Blatchford, P. and Chowne, A. (2007) Improving the effectiveness of collaborative group work in primary schools: effects on science attainment. British Educational Research Journal, 33, 5, 663-680.

Baines, E., Rubie-Davies, C. and Blatchford, P. (2009) Improving pupil group work interaction and dialogue in primary classrooms: results from a year-long intervention study. Cambridge Journal of Education, 39, 1, 95 -117 .

Ballantine, J. and Larres, P.M. (2007) Cooperative learning: a pedagogy to improve students' generic skills? Education and Training, 49, 2, 127-137.

Bellmore, A. (2011) Peer rejection and unpopularity: associations with GPAs across the transition to middle school. Journal of Educational Psychology, 103, 282-295.

Blatchford, P., Kutnick, P., Baines, E. and Galton, M. (2003) Toward a social pedagogy of classroom group work. International Journal of Educational Research, 39, 1-2, 153-172.

Bloyce, J. and Frederickson, N. (2012) Intervening to improve the transfer to secondary school. Educational Psychology in Practice, 28, 1, 1-18.

Braun, V. and Clarke, V. (2006) Using thematic analysis in psychology. Qualitative Research in Psychology, 3, 2, 77-101.

British Psychological Society (2014) Code of Human Research Ethics. Online at https://www.bps.org.uk/news-and-policy/bps-code-humanresearch-ethics-2nd-edition-2014 (accessed 26/06/2018).

Bunn, H., Davis, D. and Speed, E. (2017) High school transition - an intervention that empowers children with special educational needs and improves school practice. Support for Learning, 32, 3, 213-244.

Cauley, K. and Jovanovich, D. (2010) Developing an effective transition program for students entering middle school or high school. The Clearing House: A Journal of Educational Strategies, Issues and Ideas, 80, 1, 15-25. 
Children and Families Act (2014) Chapter 6, Part 3: Children and Young People in England with Special Educational Needs or Disabilities. London: Crown Copyright.

Coffey, A. (2013) Relationships: the key to successful transition from primary to secondary school? Improving Schools, 16, 3, 261-271.

Deci, E.L. and Ryan, R.M. (1985) Intrinsic Motivation and SelfDetermination in Human Behavior. New York, NY: Plenum.

Deci, E.L. and Ryan, R.M. (2000) The "what" and "why" of goal pursuits: human needs and the self-determination of behavior. Psychological Inquiry, 11, 227-268.

Department, for Education and Department of Health (2015) Special Educational Needs and Disability Code of Practice: 0-25 years. London: Crown Copyright.

Department for Education (2017) Special Educational Needs in England: January 2017. Annesley, Nottinghamshire: Crown Copyright.

Dolan, Paul, Leat, David, Mazzoli Smith, Laura, Mitra, Sugata, Todd, Liz and Wall, Kate. (2013) Self-organised learning environments (SOLEs) in an English school: an example of transformative pedagogy? Online Education Research Journal, 3, 11.

Evangelou, M., Taggart, B., Sylva, K., Melhuish, E., Sammons, P. and Siraj-Blatchford, I. (2008) What Makes a Successful Transition from Primary to Secondary School? Research Report No DCSF-RR019. Department for Children, Schools and Families.

Field, S. and Hoffman, A. (2002) Preparing youth to exercise selfdetermination: quality indicators of school environments that promote the acquisition of knowledge, skills, and beliefs related to self-determination. Journal of Disability Policy Studies, 13, 2, 114-119.

Foley, T., Foley, S. and Curtin, A. (2016) Primary to post-primary transition for students with special educational needs from an Irish context. International Journal of Special Education, 31, 2, 1-27. 
Galton, M., Gray, J. and Ruddock, J. (1999) The impact of school transitions and transfers on pupil progress and attainment. London: DfEE Research Report No.131.

Galton, M., Gray, J., Ruddock, J., Berry, M., Demetriou, H., Edwards, J., Goalen, P., Hargreaves, L., Hussey, S., Pell, T., Schagen, I. and Charles, M. (2003) Transfer and Transitions in the Middle Years of Schooling (714): Continuities and Discontinuities in Learning. Research Report RR443. London: DfES.

Galton, M. and Morrison, I. (2000) Concluding comments. Transfer and transition: the next steps. International Journal of Educational Research, $33,443-449$.

Graham, C. and Hill, M. (2003) Negotiating the transition to secondary school. SCRE. Spotlight 89. (Online at https://files.eric.ed.gov/fulltext/ED482301.pdf) Accessed 18/04/19.

Harri-Augstein, E. and Thomas, L. (1991) Learning Conversations: The Self-Organized Learning Way to Personal and Organizational Growth. London: Routledge \& Kegan Paul.

Hebron, J. (2017) The transition from primary to secondary school for students with autism spectrum conditions. In:C. Little (Ed.) Supporting Social inclusion for Students with Autism Spectrum Disorders: Insights from Research and Practice, pp. 84-99. London: Routledge.

Hughes, L., Banks, P. and Terras, M. (2013) Secondary school transition for children with special educational needs: a literature review. Support for Learning, 28, 1, 24-34.

Hodson, P., Baddeley, A., Laycock, S. and Williams, S. (2005) Helping secondary schools to be more inclusive of year 7 pupils with SEN. Educational Psychology in Practice, 21, 1, 53-67.

Hoffman, A. and Field, S. (1995) Promoting self-determination through effective curriculum development. Intervention in School and Clinic, 30, $3,134-141$. 
Hui, E. and Tsang, S. (2012) Self-determination as a psychological and positive youth development construct. The Scientific World Journal, 2012, $1-7$.

Jindal-Snape, D. and Foggie, J. (2008) A holistic approach to primarysecondary transitions. Improving Schools, 11, 1, 5-18.

Johnson, D.W. and Johnson, R. (1989) Cooperation and Competition: Theory and Research. Edina, MN: Interaction Book Company.

Johnson, D.W. and Johnson, T.R. (1999) Cooperative Learning and Achievement. In: D. Kluge, S. McGuire, D. Johnson andR. Johnson (Eds.) Cooperative Learning: JALT Applied Materials, pp. 23-37. New York: Greenwood Press Inc.

Johnson, D. and Johnson, R. (2002a) Cooperative learning and social interdependence theory. Theory and Research on Small Groups. Social Psychological Applications to Social Issues, 4, 9-35.

Johnson, D.W. and Johnson, R. (2002b) Cooperative learning methods: a meta-analysis. Journal of Research in Education, 12, 1, 5-14.

Johnson, D.W. and Johnson, R. (2005) New developments in social interdependence theory. Psychology Monographs, 131, 4, 285-358.

Johnson, D.W. and Johnson, R. (2008) Social interdependence theory and cooperative learning: the teacher's role. In R. Gillies, A. Ashman and J. Terwel (eds), The Teacher's Role in Implementing Cooperative Learning in the Classroom. Computer Supported Collaborative Learning Series, pp. 9-37. Vol. 8, 2008, New York: Springer.

Jolliffe, W. (2007) Cooperative Learning in the Classroom: Putting it into Practice (first edition). Thousand Oaks: Paul Chapman Publishing.

Jones, P. (2013) Adult mental health disorders and their age at onset. British Journal of Psychiatry, 20, 54, s5-s10.

Lee Looi Chng, V. and Coombs, S.J. (2004) Applying Self-organised Learning to develop critical thinkers for learning organisations: a 
conversational action research project. Educational Action Research, 12, 3, $363-386$.

Lovey, J. (2002) Supporting Special Educational Needs in Secondary School Classrooms (second edition). London: David Fulton Publishers.

Lucey, H. and Reay, R. (2000) Identities in transition: anxiety and excitement in the move to secondary school. Oxford Review of Education, 26, 2, 191-205.

Lucey, H. and Reay, D. (2010) Identities in transition: anxiety and excitement in the move to secondary school. Oxford Review of Education, 26, 2, 191-205.

Maras, P. and Aveling, E-L. (2006) Students with special educational needs: transitions from primary to secondary school. British Journal of Special Education, 33, 4. Wiley online library onlinelibrary.wiley.com (accessed 18 April 2019).

Measor, L. and Woods, P. (1984) Changing Schools: Pupil Perspectives on Transfer to a Comprehensive. Milton Keynes: Open University Press.

McGee, C., Ward, R., Gibbsons, J. and Harlow, A. (2003) Transition to secondary school: a literature review. Report to the Ministry of Education, New Zealand. Online at http://researchcommons.waikato.ac.nz/handle/10289/4340 (accessed 27 June 2018).

Mitra, S. (2012) Beyond the Hole in the Wall: Discover the Power of SelfOrganized Learning. New York: TED Books.

Mitra, S. and Dangwal, R. (2010) Limits to self-organised learning: the Kalikuppam experiment. British Journal of Educational Technology, 41, 5, 672-688.

Neal, S., Rice, F., Ng-Knight, T., Riglin, L. and Frederickson, N. (2016) Exploring the longitudinal association between interventions to support the transition to secondary school and child anxiety. Journal of Adolescence, $50,31-43$. 
Niemiec, C.P. and Ryan, R.M. (2009) Autonomy, competence, and relatedness in the classroom: applying self-determination theory to educational practice. Theory and Research in Education, 7, 2, 133-144.

Reissner, S. (2004) Learning by storytelling? Narratives in the study of work-based learning. Journal of Adult and Continuing Education, 10, 2, 99 -113 .

Reissner, S. (2008a) Narrative and storytelling: new perspectives on coaching. The International Journal of Mentoring and Coaching, 6, 1-5.

Reissner, S.C. (2008b) Narratives of Organisational Change and Learning: Making Sense of Testing Times. Cheltenham: Edward Elgar.

Rice, F., Frederickson, N. and McManus, C. (2013) Predicting successful and difficult transitions to secondary school. Nuffieldfoundation.org (accessed 18 April 2019).

Rice, F., Frederickson, N. and Seymour, J. (2011) Assessing pupil concerns about transition to secondary school. British Journal of Educational Psychology, 81(2), 244-263.

Rickards, T. and MOGER. S., (2000) Creative leadership processes in project team development: an alternative to Tuckman's stage model. British Journal of Management, 11, 4, 273-83.

Ryan, R.M. and Deci, E.L. (2000) Self-determination theory and the facilitation of intrinsic motivation, social development, and well-being. American Psychologist, 55, 68-78.

Scanlon, G., Barnes-Holmes, Y., McEnteggart, C., Desmond, D. and Vahey, N. (2015) The experiences of pupil's with SEN and their parents at the stage of pre-transition from primary to post-primary school. European Journal of Special Educational Needs, 31(1), 44-58.

Stoll, L., Stobart, G., Martin, S., Freeman, S., Freedman, E., Sammmons, P. and Smees, R. (2003) Preparing for Change: Evaluation of the Implementation of the Key Stage 3 Pilot Strategy, Final Report. London: Department for Education and Skills. 
Thomas, L. and Harri-Augstein, S. (1985) Self Organised Learning: Foundations of A Conversational Science for Psychology. Routledge and Kegan Paul.

Tobbell, E. (2014) Transition from primary to secondary school: a case study from the United Kingdom. InA.B. Liegmann, I. Mammes andK. Racherbäumer (eds), Facetten von Übergängen im Bildungssystem: Nationale und internationale Ergebnisse empirischer Forschung, pp. 251 -264. Germany: Waxmann Verlag GMBH.

Topping, K. (2011) Primary-secondary transition: differences between teachers' and children's perceptions. Improving Schools, 14, 3, 268-285.

Tuckman, Bruce W. (1965) Developmental sequence in small groups. Psychological Bulletin, 63, 6, 384-399.

UN General Assembly, Convention on the Rights of the Child, 20 November (1989) United Nations. Treaty Series, vol. 1577, p. 3, [Online at: http://www.refworld.org/docid/3ae6b38f0.html] Accessed 28/06/18.

van Ryzin, M.J. and Roseth, C.J. (2018) Cooperative learning in middle school: a means to improve peer relations and reduce victimization, bullying, and related outcomes. Journal of Educational Psychology. Advance online publication. https://doi.org/10.1037/edu0000265.

Waters, L., Barsky, A., Ridd, A. and Allen, K. (2015) Contemplative education: a systematic, evidence-based review of the effect of meditation interventions in schools. Educational Psychology Review, 27, 1, 103-104.

Waters, S.K., Lester, L. and Cross, D. (2014) Transition to secondary school: expectation versus experience. Australian Journal of Education, $58,2,153-166$.

Waters, S.K., Lester, L., Wenden, E. and Cross, D. (2012) A Theoretically grounded exploration of the social and emotional outcomes of transition to secondary school. Australian Journal of Guidance and Counselling, 22, 2, 190-205. 
Wehmeyer, M. (1999) A functional model of self-determination: describing development and implementing instruction. Focus on Autism and Other Developmental Disabilities, 14, 1, 53-61.

Wendt, S., Hipps, J., Abrams, A., Grant, J., Valosek, L. and Nidich, S. (2015) Practicing transcendental meditation in high schools: relationship to well-being and academic achievement among students. Contemporary School Psychology, 19, 4, 312-319.

West, P., Sweeting, H. and Young, R. (2010) Transition matters: Pupils' experiences of the primary-secondary school transition in the west of Scotland and consequences for well-being and attainment. Research Papers in Education, 25, 1, 21-50.

Whetten, D.A. and Cameron, K.S. (2007) Developing Management Skills (seventh edition). Upper Saddle River, NJ: Prentice-Hall.

Wisner, B. (2014) An exploratory study of mindfulness meditation for alternative school students: perceived benefits for improving school climate and student functioning. Mindfulness, 5, 6, 626-638.

Wolpe, J. (1958) Psychotherapy by Reciprocal Inhibition. Stanford, CA: Stanford University Press.

Zeedyk, M.S., Gallacher, J., Henderson, M., Hope, G., Husband, B. and Lindsay, K. (2003) Negotiating the transition from primary to secondary school: perceptions of pupils, parents and teachers. School Psychology International, 24, 1, 67-79. 